\title{
CAMBIASSU

\section{lmagens do fogo no Pantanal: reflexões acerca dos simbolismos na fotografia ambiental de Araquém Alcântara}

\author{
Images of fire in the \\ Pantand: reflections on \\ symbolism in \\ environmental photography \\ by Araquém Alcântara
}

\section{Rayane Lacerda}

Mestre em Comunicação pelo PPGCOM/UFRGS, sob orientação da Prof. ${ }^{\circ}$ Dr. a Ana Taís Martins, e graduada em Jornalismo pela UFPel. Membro do Imaginalis - Grupo de Pesquisa sobre Comunicação e Imaginário (CNPq/UFRGS). E-mail: raylavisiargmail.com.

\section{Anelise De Carli}

Professora e pesquisadora da Associação de Pesquisas e Práticas em Humanidades (APPH). Doutora e Mestre em Comunicação e Informação pela Universidade Federal do Rio Grande do Sul (UFRGS) com estágio (PDSE/CAPES) no Institut de Recherches Philosophiques de Lyon (IRPhiL) da Université Jean Moulin Lyon 3. E-mail: anelisedecarliargmail.com 


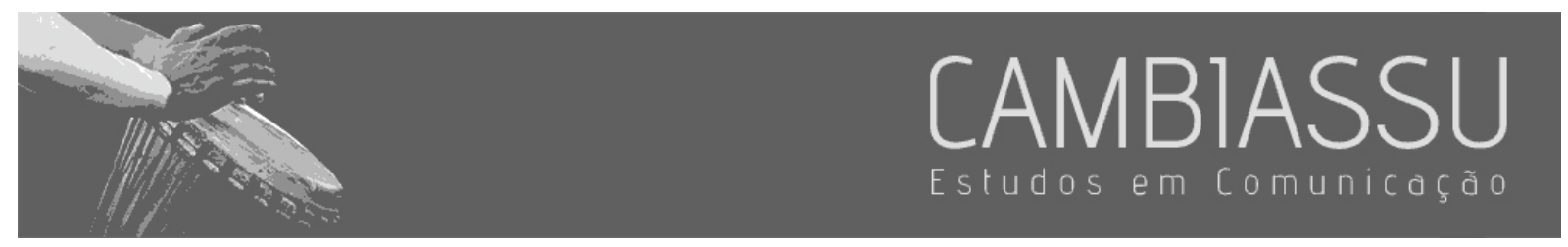

\section{Resumo}

Tomando a civilização da imagem como ponto de partida, o artigo discute as particularidades da fotografia ambiental no que tange a experiência através da imagem, o (re)encantamento do mundo pela via da imaginação e as questões ambientais que cercam as queimadas ocorridas no Pantanal, em 2020. Para tanto, faz uma leitura simbólica das fotografias de Araquém Alcântara sobre o acontecimento em questão, investigando as estratégias de enfrentamento do mundo construídas pelo imaginário antropológico. Conclui-se que o fotógrafo faz uso de uma estratégia combativa, buscando compensar a narrativa destruidora ao exaltar as belezas brasileiras.

Palavras-chave: Fotografia; Imagem; Imaginário; Araquém Alcântara; Meio Ambiente.

\section{Abstract}

Taking the civilization of image as a starting point, the article discusses the particularities of environmental photography regarding the experience through the image, the (re)enchantment of the world through the imagination and the environmental issues surrounding the fires that occurred in the Pantanal, in 2020. To do so, it makes a symbolic reading of the photographs by Araquém Alcântara about the event in question, investigating the strategies for confronting the world constructed by the anthropological imaginary. It is concluded that the photographer uses a combative strategy, seeking to compensate the destructive narrative by exalting the Brazilian beauties.

Keywords: Photography; Image; Imaginary; Araquém Alcântara; Environment. 


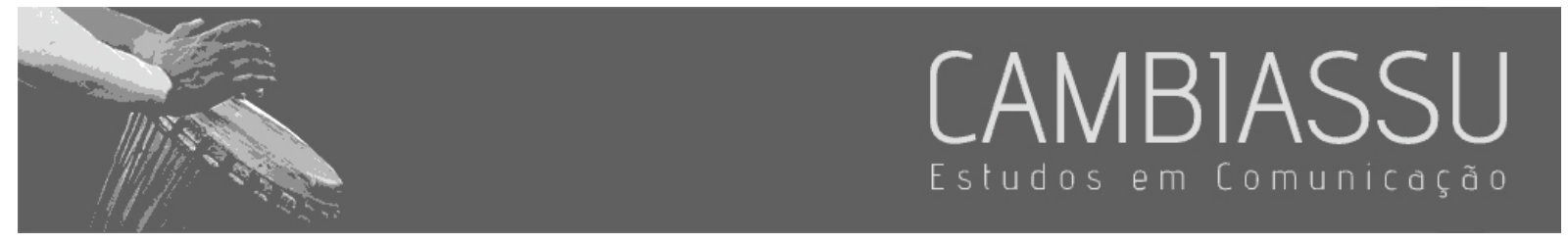

\section{Introdução}

É indiscutível a importância que a fotografia desempenha no nosso cotidiano, já que vivemos cercados constantemente de imagens nas práticas comunicativas do mundo contemporâneo. O Instagram, por exemplo, é uma plataforma de rede social criada especialmente para o compartilhamento de imagens técnicas, sejam elas de arquivos pessoais ou reproduzidas por autoria de terceiros. O protagonismo das imagens como técnica da comunicação contemporânea indica a confluência do advento da informatização das comunicações e da hiperconexão global, resultando no que hoje se entende por "civilização da imagem" (AUTOR, 2020).

Nessas plataformas, entre as inúmeras possibilidades de temáticas abordadas, o meio ambiente e a relação entre humano e natureza são pautas que ganham cada vez mais espaço, à medida que as consequências do desenvolvimentismo capitalista desenfreado são notadas nas cidades. As mudanças climáticas já mostram o calor e o frio excessivos e a diminuição na periodicidade das chuvas como suas consequências mais visíveis (DAMÁSIO, 2020), o que potencializa a discussão sobre as problemáticas ambientais tanto na imprensa quanto nas mídias sociais. As pautas ambientais estão presentes de diversas maneiras, seja tratando de questões políticas que envolvem o meio ambiente ou incentivando mudanças nos hábitos pessoais ${ }^{1}$. Nesse cenário, diversos fotojornalistas ambientais passaram a divulgar trabalhos nos principais biomas brasileiros, característicos do patrimônio ambiental nacional, como a Amazônia, o Cerrado e o Pantanal. Além de divulgar suas fotografias, transformando as plataformas de rede social em portfólio profissional, essa divulgação, dado o uso social dessas redes, possivelmente potencializa a mensagem dessas narrativas fotográficas, uma vez que ela privilegia o compartilhamento de informações visuais, podendo oferecer aos interessados nas pautas ambientais estratégias outras de aproximação com o tema. Dada a

\footnotetext{
1 Considerando, por exemplo, os diversos perfis nas plataformas de redes sociais que têm como objetivo o incentivo a comportamento e consumo sustentáveis, como a diminuição da produção de resíduos ou a adoção de dietas vegetarianas/veganas.
} 


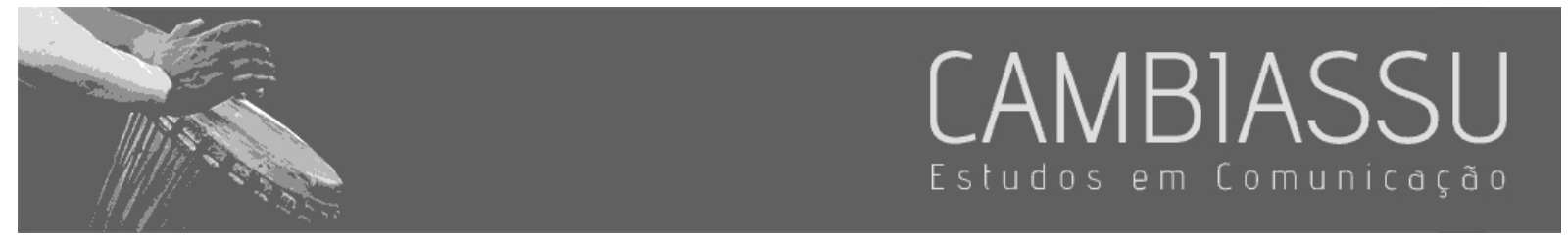

presença constante das pautas ambientais nos ambientes sociais de produção e consumo de imagens técnicas, nos interessa refletir sobre o papel desempenhado pela fotografia na cobertura dessas problemáticas.

Esse é o caso de Araquém Alcântara, fotógrafo de natureza, brasileiro amplamente reconhecido internacionalmente com uma carreira que já soma 50 anos. No seu perfil público no Instagram ${ }^{2}$, ele compartilha fotografias que registra como profissional andarilho, criando uma forma mais acessível de contato com suas imagens, sem a necessidade, por exemplo, de adquirir um livro em que estejam presentes.

A situação dos biomas brasileiros se torna mais crítica e irreversível a cada ano (LEMOS, 2021). No segundo semestre de 2020, o Pantanal virou foco de atenção na imprensa e nas plataformas de redes sociais devido a incêndios de grandes proporções, crise que levantou discussões sobre os rumos para os quais as inexpressivas políticas de preservação nacionais estão levando o patrimônio ambiental brasileiro. De um lado, há a hipótese de o fogo ter origem espontânea e natural devido a queimadas de limpeza autorizadas, mas que acabaram saindo do controle e, de outro, uma perspectiva crítica que levanta possíveis indícios criminais nas ações de fazendeiros e pecuaristas que estariam promovendo deliberadamente queimadas para a criação de áreas de pasto (RODRIGUES, 2020).

Nesse contexto, buscamos compreender os aspectos da cobertura ambiental apresentados em fotografias, bem como as motivações imaginárias ali presentes, com recorte no trabalho de Araquém Alcântara sobre as queimadas ocorridas no Pantanal enquanto problemática aqui abordada. Para tanto, lançamos mão da noção de fotografia ambiental (AUTORES, 2021) e dos estudos do imaginário (MARTINS, 2020; DURAND, 1997) que conversam com a ideia do (re)encantamento do humano (UNGER, 1991; 2009), com as estratégias de enfrentamento a uma monocultura da mente (SHIVA, 2003) e com as características específicas do jornalismo ambiental (GIRARDI et al., 2012) -

\footnotetext{
2 Disponível em: <https://www.instagram.com/araquemoficial/>. Acesso em: 5 jul. 2021.
} 


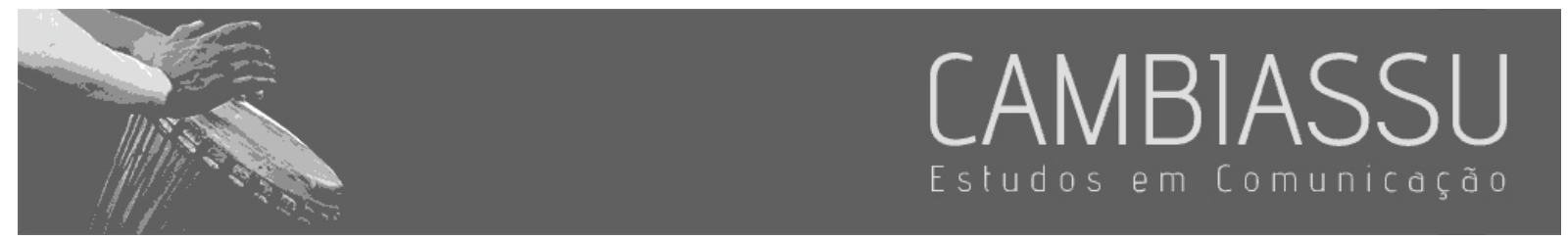

do qual também participa o preceito do ativismo ecológico (BELMONTE, 2015). Perguntamos: qual organização do imaginário, ou seja, qual é a estratégia simbólica de enfrentamento, que está sendo mobilizada pela cobertura fotográfica ambiental em questão?

\section{Aspectos do imaginário como inconsciente da cultura}

Na região mato-grossense, epicentro do fogo que tomou conta do Pantanal, ainda em 2020, Alcântara caminhou e registrou o que de mais terrível estava presente, como animais mortos, animais em fuga, brigadistas em número bastante reduzido e sem ferramentas de trabalho, e árvores carbonizadas. Entretanto, em entrevista ao Portal G1 (LEITE, 2020), em setembro do mesmo ano, mês de ápice das queimadas, o fotógrafo narra um paralelo interessante: "Eu vi animais resistindo, tentei me fixar nisso, na beleza desses animais apesar de todo o fogo, na grandeza de gente anônima que tem um sentido de pátria, que tem realmente amor ao país" (ALCÂNTARA, 2020, s/p). O fato de Alcântara ter buscado, em meio ao caos no incêndio no Pantanal, o retrato da beleza e da vida, é um paradoxo interessante para quem se interessa em pensar o funcionamento das imagens.

Segundo o filósofo Gilbert Durand (1997), o medo da morte é o motor primordial que faz nascer a imaginação como resposta à angústia tenebrosa do fim da vida humana e material. Como bem resume Ana Taís Martins (2020, p. 58), precursora dos estudos durandianos na área da Comunicação no Brasil, "[...] o imaginário nasce da consciência do tempo que passa, ou seja, da consciência de perecibilidade do corpo". Trazendo esse pensamento para a nossa discussão sobre fotografia ambiental, poderíamos pensar na "imaginação" em Durand como substitutivo para a "beleza" que Araquém procurava.

Essa resposta da imaginação à passagem do tempo tem por resultado três lógicas de organização das imagens, conforme Durand (1997) em sua tese sobre As Estruturas Antropológicas do Imaginário que se dividem em regime diurno e regime noturno. Cabe ressaltar que a noção de 


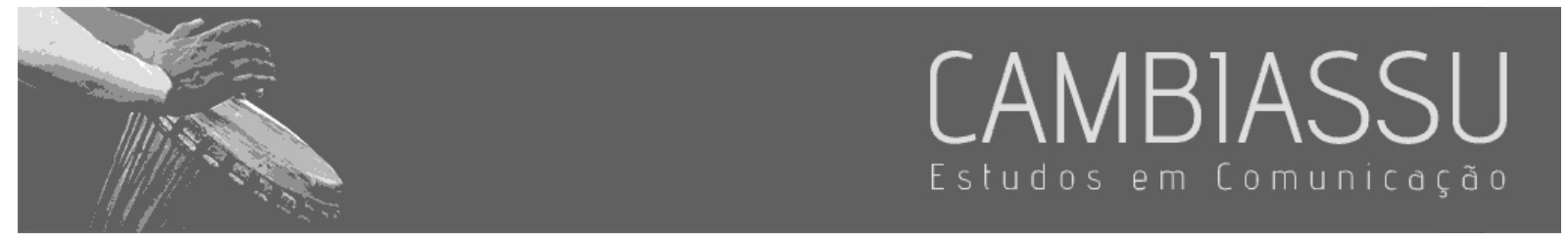

"imagem", nos estudos no imaginário durandianos, não se refere a um sinônimo para a fotografia ou outra imagem técnica visual - conforme Autor (2020) a partir da abordagem de Flusser (2011). A imagem, na esteira de Gilbert Durand (1995), não seria um objeto técnico, mas o nome dado a uma experiência existencial vivida pelos sujeitos quando em contato com um sentido simbólico3. Conforme já tratamos em outro momento (AUTORES, 2019), as fotografias de Alcântara se valem da organização de sentido prevista pelo regime diurno, também chamado de regime heroico, que elabora em suas narrativas visuais batalhas a serem travadas e procura ferramentas de luta contra a morte. Podemos antever o mesmo funcionamento aqui na declaração feita por ele, quando procura registrar a beleza dos animais em meio ao fogo destruidor. A existência de polos opositores em situação de mútuo aniquilamento é a estrutura figurativa descritora do regime diurno do imaginário (DURAND, 1997). Alcântara, tomando essa lógica como propulsora de suas fotografias, não se contenta em apenas registrar o horror ali presente: ele vai além e mostra possíveis maneiras de enfrentá-lo. Em outras palavras, as fotografias de Alcântara dinamizam o olhar para a beleza pormenorizada, colocada em foco metafórico e literalmente, deixando as queimadas no papel de contexto de fundo, palco onde se dá a ação dos detalhes e gestos que ele traz para o primeiro plano.

\section{Aspectos da fotografia ambiental como forma de olhar}

Como já exploramos em outros estudos (AUTORES, 2021), a noção de fotografia ambiental advém do entrecruzamento dos aspectos da fotografia e do jornalismo que tem o meio ambiente como atravessamento constitutivo, sendo não apenas uma prática sobre a natureza, ou seja, caracterizandose por uma temática especializada, conforme indicam Ilza Girardi e colaboradores (2012), mas sendo também uma narrativa que se constrói com a natureza. Essa perspectiva dá à prática características específicas, como a pluralidade de vozes, a visão sistêmica da problemática em questão e uma

\footnotetext{
${ }^{3}$ Este termo será melhor aprofundado na seção de análise das fotos pelo método da leitura simbólica.
} 


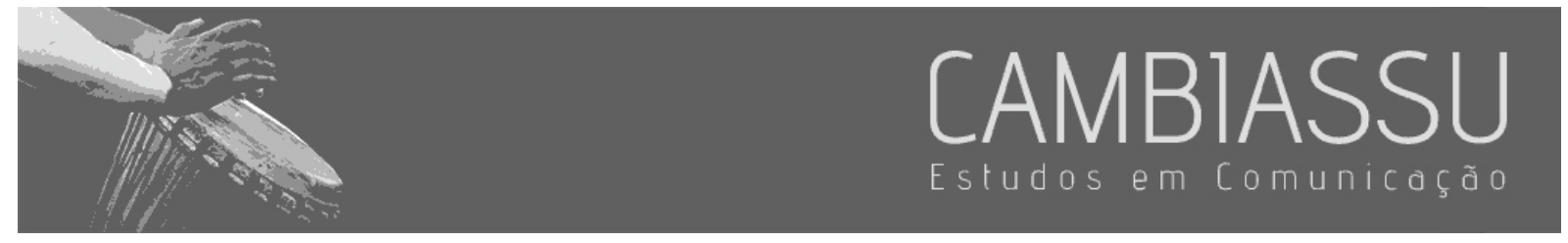

abordagem independente que vai "[...] além de uma cobertura factual e programada" (GIRARDI et al., 2012, p. 137). A fotografia, inserida nesse contexto, adquire alta relevância, já que acrescenta o elemento visual nessa teia de sentidos e interpretações imbricados e que cumprem para desativar uma perspectiva antropocêntrica, ao retirarem o humano do centro da narrativa e colocando-o como ator interconectado aos elementos naturais através do elo da vida.

Quando inserida na prática jornalística, a fotografia se adapta às funções informacionais de construção dos acontecimentos. Mas essa adaptação não ocorre sem preservar algumas características particulares da linguagem fotográfica. Sendo um tipo de imagem, a fotografia de imprensa, mesmo que seja acionada por um dispositivo discursivo específico como o do jornalismo e nesse contexto trabalhe em conjunto com a legenda e o texto de uma notícia, também produz sentido através do impacto visual que provoca. Quando a fotografia traz o meio ambiente como atravessamento primordial na construção da informação, tanto o jornalismo ambiental quanto a própria fotografia podem ganhar dimensões frutíferas: o jornalismo ambiental, por ter a abordagem visual a seu favor no que se trata de afetar e comover sobre a urgência de olhar para as problemáticas do meio ambiente; e a fotografia, por alcançar níveis de sentido que perpassam um ativismo ecológico (BELMONTE, 2015).

Quando ambas as práticas, o jornalismo ambiental e a fotografia, se unem num suporte de comunicação em comum, é possível reconhecer outras particularidades possíveis. Em primeiro lugar, a poética fotográfica e a busca por um olhar artístico nas composições, são capazes de encantar, cativar e arrebatar os sujeitos que entram em contato com a narrativa do jornalismo de cunho ambiental que se faz presente através da aparição em forma de imagens. Por outro lado, esse entrelaçamento entre práticas potencializa o ativismo ecológico, que ajuda a pensar as características da fotografia ambiental tais como a capacidade de comunicar para transformar o olhar diante a natureza, social e politicamente, não apenas informando de modo superficial e corriqueiro (BELMONTE, 2015). Tal papel ativista pode ser visto na figura de Alcântara, pois se trata de um profissional comprometido com a 


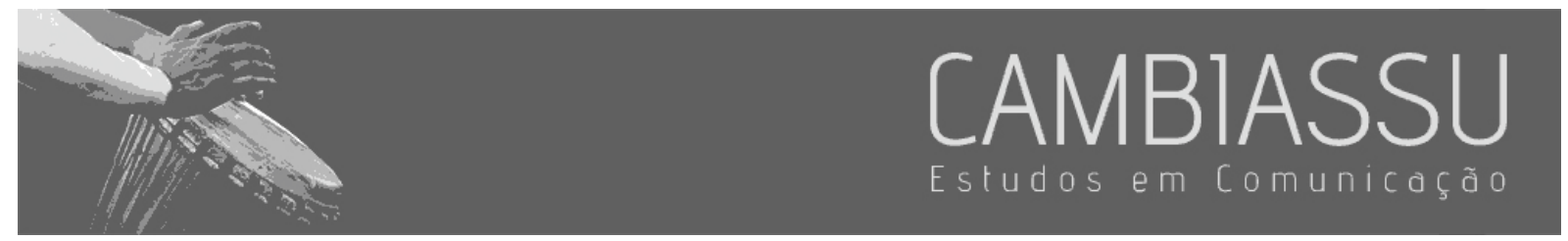

causa ambiental, alguém envolvido com a diversidade de vozes que o ajuda a "[...] olha[r] além das consequências em busca das causas e soluções dos problemas ambientais" (BELMONTE, 2015, p. $68)$.

Para tanto, de maneira resumida, a fotografia ambiental seria “[...] a visão orgânica e artística da existência, apresentada, compartilhada e informada por meio da linguagem visual fotográfica, sendo capaz de mobilizar e transformar o mundo em que se vive" (AUTOR, 2019, p. 284). Isso conduz ao fenômeno da sustentabilidade do olhar (AUTOR; 2019) que está atrelada à fotografia ambiental, uma vez que a união de ambos os conceitos numa terceira noção fortalece as oportunidades de transformação social. Essa transformação não ocorre pelo sentido da visão que é direcionado a uma fotografia ambiental, mas pelo olhar que diz respeito às profundezas humanas, coletivas e antropológicas de uma problemática que se apresenta também com ajuda de uma fabulação imagética. Olhar, aqui, não se refere apenas a vermaterial e organicamente, mas a sentir a presença da natureza e a urgência de compreendê-la como diretora das narrativas junto das inúmeras subjetividades ao seu redor. Nossos passos agora se dirigem para o entendimento de como poderia se dar a construção dessa forma específica de olhar motivada pela fotografia ambiental.

\section{Imaginar para (re)encantar o olhar}

As subjetividades e as comoções profundas que estão presentes na sustentabilidade da fotografia ambiental (AUTOR, 2019) podem ser pensadas, também, pela perspectiva teórica do imaginário antropológico (BARROS, 2016), que propõe a necessidade de (re)encantar o olhar humano sobre a natureza. Esse ponto de vista é do nosso interesse justamente porque: "A natureza dessacralizada deixa de ser sujeito para ser objeto: o diálogo e a troca se transformam em projeto de controle e dominação" (UNGER, 1991, p. 25). Essas considerações nos abrem para algumas ramificações possíveis: primeiro, o papel do humano na relação desigual e injusta que mantém com a 


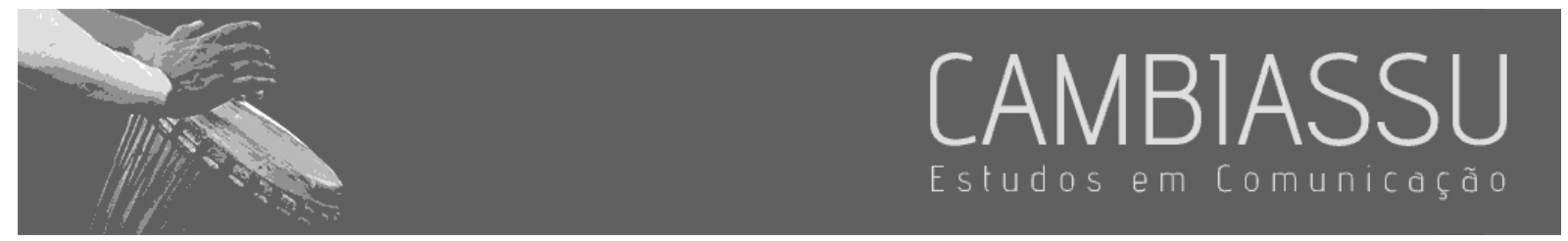

natureza ao redor; segundo, a necessidade de se pensar para além das monoculturas da mente (SHIVA, 2003), ampliando as formas de acesso ao conhecimento para modos a-racionais, e, por último, o aspecto coletivo para o qual o imaginário antropológico (DURAND, 1997) aponta como uma saída possível para atingirmos a preservação da vida e a manutenção de uma perspectiva ecológica através da fotografia ambiental.

Nancy Unger (2009) questiona o termo crise que hoje faz parte do vocabulário tanto acadêmico quanto do senso comum. Segundo a autora, muito se fala em crise ambiental, crise de paradigma, crise política, crise moral etc., mas pouco se pergunta sobre o ponto central das tensões e instabilidades que participam da vida atual: o sujeito homem que acredita ter uma liberdade desmedida, a qual advém de um mecanismo de recusa a sua dependência do planeta (UNGER, 2009). Ainda para Unger (2009), a filosofia de Francis Bacon, com a sua máxima sobre dominar e domesticar a Natureza, que encontrou tanta reverberação no mundo moderno, é uma das precursoras desse pensamento mecanicista que nos trouxe ao desencantamento do mundo, a perda de sacralidade dos elementos naturais que permeiam o cotidiano e são as matérias-primas dos recursos usufruídos pelo humano. Entretanto, se saímos da perspectiva de que serhumano não se trata somente do indivíduo atual e das suas ações sobre o mundo, mas de um sujeito também arcaico que nos leva a considerar a coletividade que está presente num prisma cósmico sobre o meio ambiente, chegamos a outra compreensão. Um sentido que entende "[...] o ser humano na plena realização de suas potencialidades; o homem microcosmos no sentido de que realiza a harmonização de todas as forças cósmicas que nele atuam, a ponto de poder ser aquele que reflete o arco-íris, que reflete o céu [...]" (UNGER, 1991, p. 61). Essas questões sobre o (re)encantamento do humano, trazidas pela autora, muito se relacionam com a perspectiva antropológica dos estudos do imaginário de vertente durandiana, para os quais natureza e homem não se separam, já que ambos são elementos importantes de uma mesma corrente - a vida. 


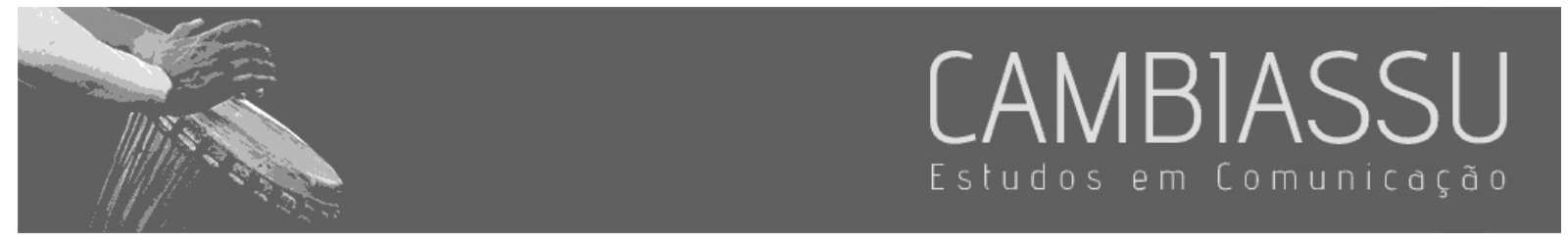

Unger (1991) aponta o mito como uma narrativa imagética que não faz parte da grande História, o que também é uma das trincheiras do imaginário de Gilbert Durand. Para Durand (1997), o mito é uma narrativa a-história e a-racional responsável por organizar, pelo método da convergência, a genealogia do simbólico enquanto resultante de pulsões profundas. Do mesmo modo que Unger (1991, p. 31) fala sobre "a dimensão mítica constitutiva do homem", os estudos do imaginário propõem pensar o mito como uma realidade arcaica que não depende dos acontecimentos históricos, pois antecede os fatos sociais uma vez que se afasta de uma narrativa irreal, lendária ou folclórica (MARTINS, 2020).

Essa narrativa arcaica, como organização sagrada e primordial do simbólico, nos leva a diferenciar o próprio termo simbólico, pois, aqui, ele se afasta de uma noção codificada e arbitrariamente designada. Nesse sentido, a ideia do símbolo deixa de ser uma propriedade que pode ser representada a partir de fenômenos ou fatos e passa a ser uma apresentação da experiência vivida que carece de uma condição de acontecimento (MARTINS, 2020).

A descrição metódica de imagens e sua inserção em um universo de referências é antes um trabalho do ser cultural que há no sujeito, é um processo diacrônico, enquanto o impacto imediato que uma obra causa fala ao ser mítica, é um processo sincrônico que prescinde de explicações. É por isso que uma obra pode causar profunda impressão em um espectador que não conhece o artista, que não sabe qual o movimento estético que ele segue e se o que está representado se refere a esse ou aquele fato histórico, a essa ou àquela personagem (MARTINS, 2020, p. 56-57).

O mesmo acontece com a fotografia e sua potencialidade de abarcar os sentidos do espectador inteiramente. Quando isso ocorre, podemos falar do simbólico ali presente e de possíveis aspectos de uma narrativa mítica dominante que se apresenta nas produções humanas e culturais, indo além - ou, melhor, antecedendo ontologicamente - das representações icônicas interpretadas através de um código definido pelo pensamento lógico-dedutivo. Isso quer dizer que a presença do fogo, por exemplo, em fotografias, não seria um elemento tocante, que causa comoção e afetividade, simplesmente pelo fato de sabermos racionalmente que o fogo causa destruição e morte. Antes disso, segundo essa 


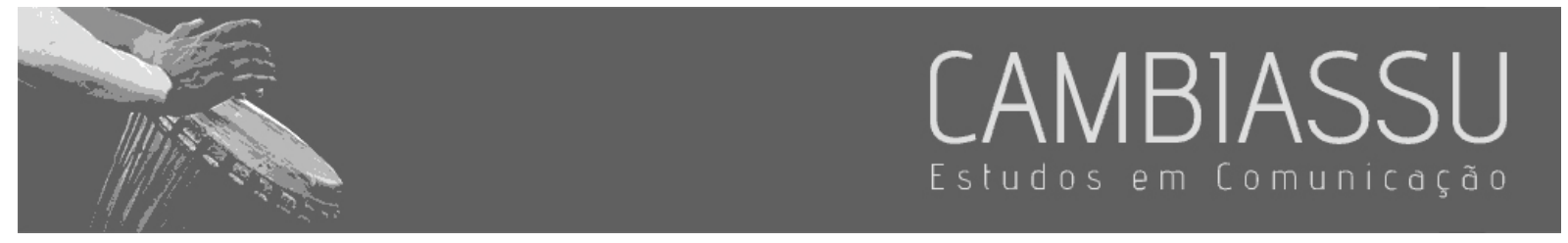

perspectiva teórica durandiana, o fogo é um elemento simbólico, antes de ser sígnico, o que significa que seu simbolismo não somente está figurado na forma visual da fotografia, mas que ele participou do processo de produção da própria fotografia. Nesse caso, segundo os regimes de imagem durandianos, o elemento do fogo pode vir a ser tanto regenerador quanto destruidor, dependendo dos simbolismos que convergem por homologia (DURAND, 1997) na experiência profunda do olhar. O fogo regenerador estaria mais próximo de um sentido de fertilidade, ao passo que o fogo destruir aproximase daquilo que finde a vida.

Pensar o simbólico e o mito nesses termos, torna-se uma chave de leitura para considerar outras maneiras possíveis de acesso ao conhecimento. Esses equacionamentos sobre a validação de outros campos do saber se relacionam com alguns elementos que compõem a noção de monoculturas da mente, de Vandana Shiva (2003). Segundo a autora, essas questões podem ser equacionadas ao olharmos para as problemáticas do modelo central de relação entre humano e meio ambiente que prioriza o consumo, o capital e a busca desenfreada por um progresso que já se mostrou insustentável (SHIVA, 2003). Esse modelo vigente é tido como o guia das práticas humanas universais, desvalorizando, negando e deslegitimando outras formas de consciência ambiental, social e política. Shiva (2003, p. 22) denomina esse processo como "colonização intelectual", já que "o primeiro plano da violência desencadeada contra os sistemas locais de saber é não considerá-los um saber". Por isso, imaginar simbolicamente não precisa ser apenas uma metáfora ou fantasia como "férias da razão" (DURAND, 1997, p. 22) tida como mecanismo principal do mundo desperto que ainda mantém influências positivistas e cartesianas. Imaginar simbolicamente pode (e deve) ser um exercício de emancipação das narrativas centradas no humano que busca a dominação da natureza e dos elementos que sustentam a própria vida no planeta, alcançando um pensamento ecológico e integral.

\section{As imagens do fogo no pantanal}




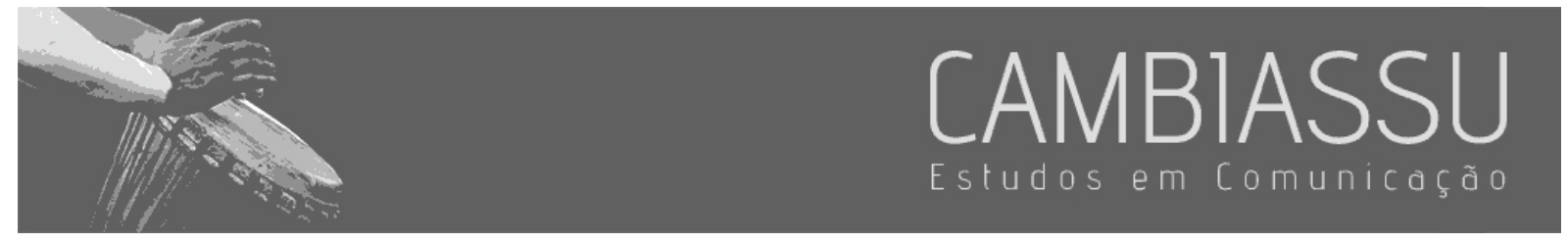

Para alcançar os objetivos propostos e os equacionamentos possíveis para as questões colocadas, lançamos mão da leitura simbólica como procedimento metodológico (BARROS, 2019) a fim de perceber os sentidos mais profundos e simbólicos das fotografias. Para tanto, nos interessa menos os aspectos técnicos usados, como enquadramento, formatos da luz, regras de composição etc., pois esse método nos instiga perceber as construções do imaginário que se dão por trás da imagem como resultado veiculado num meio de comunicação. Barros (2019, p. 140) explica a leitura simbólica como um método que nos ajuda a olhar para as fotografias de modo "[...] sintético e imersivo, num estado de receptividade à fotografia examinada, tomando o cuidado de concentrar a atenção visual sobre ela, suspendendo os pensamentos a fim de se deter o fluxo de racionalização [...]". Por isso, fazemos descrições de inquietações e possibilidades inferidas a partir do toque simbólico revelado no trabalho de Alcântara. Detemo-nos, então, nas relações criadas entre sujeito e imagem a partir das fotografias contatadas, em vez de buscar significações nas fotografias.

As fotografias de Araquém Alcântara no Pantanal, feitas durante as queimadas de 2020, escancaram a morte diante dos nossos olhos. Segundo as lógicas do imaginário antropológico, notase que o fogo, aqui, não é regenerador, pois ele destrói tudo aquilo que cruza o seu caminho, criando um ambiente desolador sobre o momento que vivemos. A morte, na construção simbólica das fotografias de Alcântara, nasce da separação entre humano e natureza, sendo o primeiro colocado como um elemento maior do que a própria grandeza do meio ambiente. Por onde passa, o fogo mata e, por isso, as fotografias trazem as facetas da morte. Entretanto, esse não é um fogo qualquer, aleatório. É como se o distanciamento dos sujeitos com a natureza - o que Unger (1991) entende como a ausência de encantamento humano - tivesse potencializado um atrito que orientou a produção das imagens mortíferas registradas por Alcântara.

Figura 1: Os macacos-prego fogem 

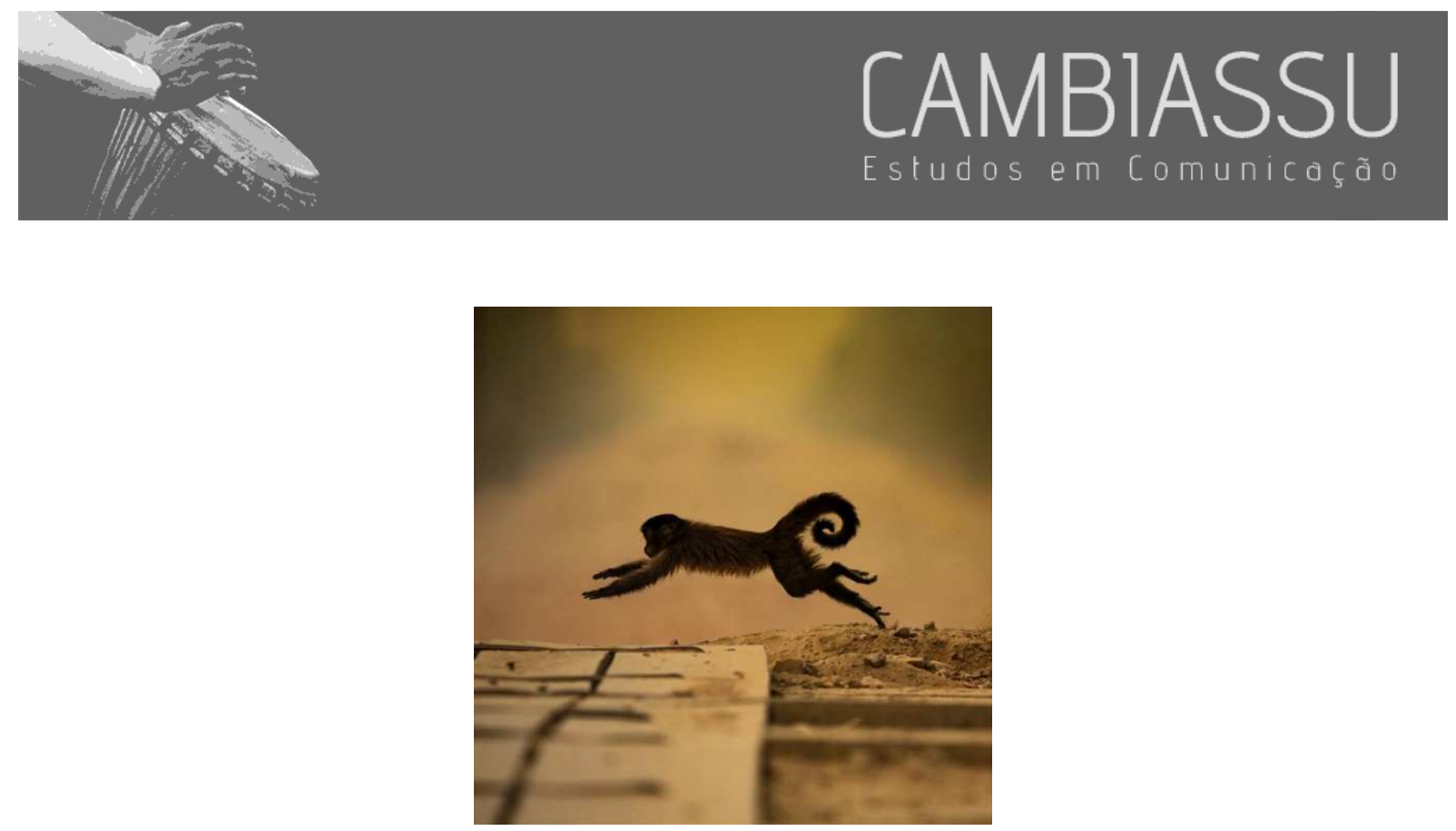

Fonte: ALCÂNTARA (2020, s/p).

Nesta fotografia, um macaco-prego foge saltando, mergulhado em alguma possibilidade de afago, de esperança de salvação no meio da cena em chamas. Ele não sabe para onde correr, apenas reconhece que precisa ter seu corpo aprofundado no ar - mesmo que seja difícil respirar em meio à fumaça que toma conta do ambiente. O fogo não precisa estar representado de forma icônica na fotografia para manifestar a destruição que provoca, pois, o gesto de mergulho fugitivo do macaco é uma das facetas tenebrosas desse calor que silencia a natureza e os seres que dela fazem parte. 0 macaco estica os braços, pequenos e delicados, em busca de um suspiro de vida.

A sensibilidade de Araquém está no ativismo ecológico (BELMONTE, 2015) que ele coloca em ação enquanto fotografia ambiental. Ele registra o fogo no Pantanal, propriamente dito, mas também faz escolhas de enquadramento e composição que mostram nuances pormenorizadas, como o macaco-prego que mergulha no ar e cai no abismo da morte.

Figura 2: Pegando fogo mesmo 

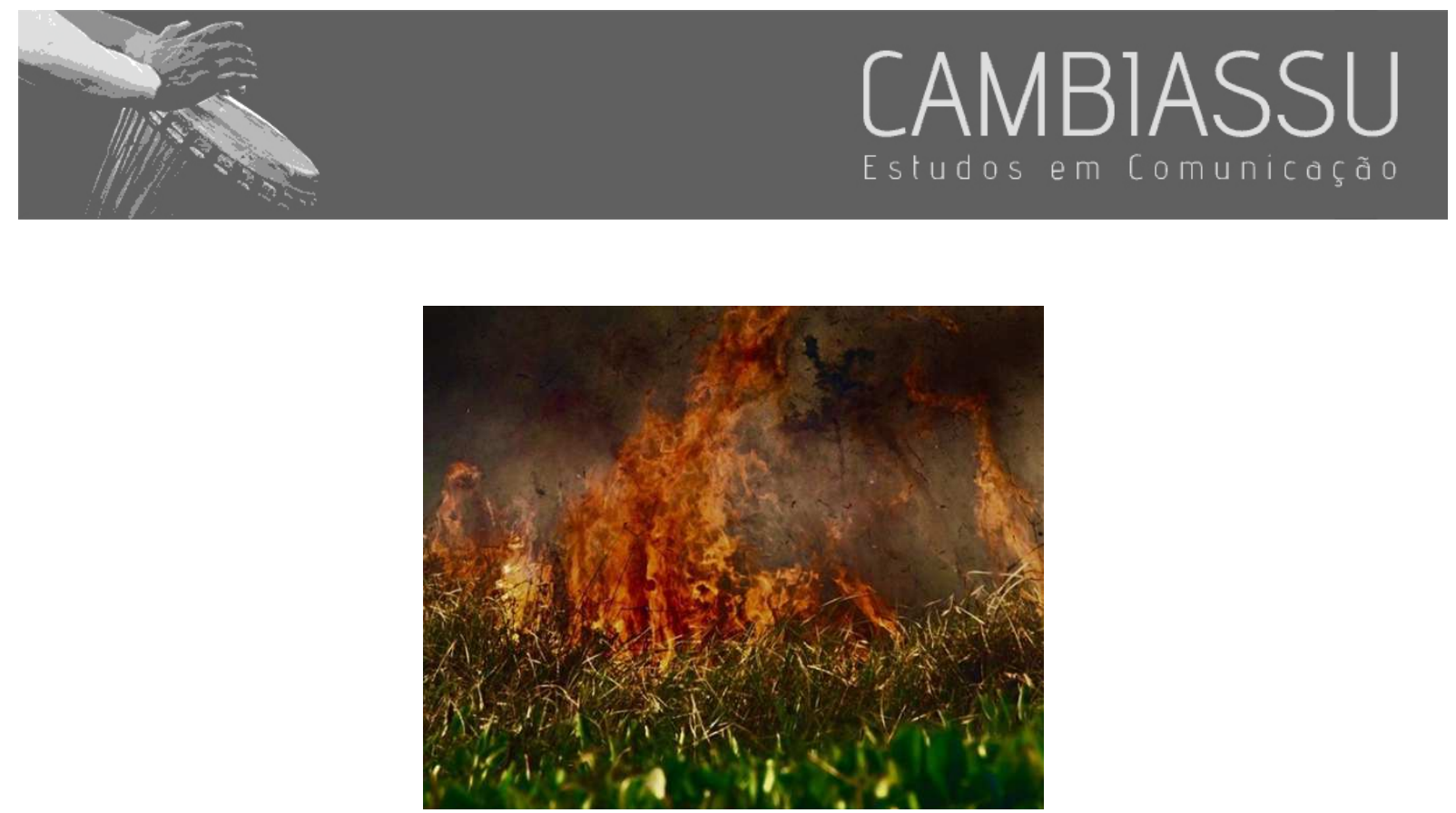

Fonte: ALCÂNTARA (2020, s/p).

Nessa fotografia, o que nos chama a atenção primeiramente é o contraste entre o fogo que queima ao fundo e o que ainda resta de mata verde e nativa, abaixo. O quadro é tomado por uma nuvem escura que emerge como resultado das mortes ocorridas no bioma brasileiro. Se nos consideramos sujeitos intrinsecamente implicados na imagem, para além de observadores/espectadores comovidos pela narrativa complexa apresentada em uma cena singular, sentimos a ameaça que ultrapassa os quadros da fotografia. Nos vemos, então, diretamente conectados aos sentidos por ela propostos, como se, presentes mesmo na cena, o fogo estivesse vindo em nossa direção com o objetivo primeiro de nos tocar, abraçar e dominar, levando-nos também para o fim da vida. Pensamos, então, se esse contraste traz aspectos do jornalismo ambiental e da explícita figuração do problema (o fogo na mata) ou se não se reporta mesmo a algo anterior, mais ligado aos dispositivos do imaginário humano, naquilo que tange a apresentação simultânea de dois elementos contraditórios. O fogo, laranja estalado; o verde vibrante das folhas; e um compreensível movimento de dominação, aniquilamento, de um pelo outro. As consequências disso saltam diretamente para o argumento socioambiental: seriam as causas (o fogo) que resultam nas consequências (a mata prestes cair em chamas), criando o retrato de toda uma crise em curso de acontecer em uma fração de segundo.

Figura 3: A paisagem agora é essa 

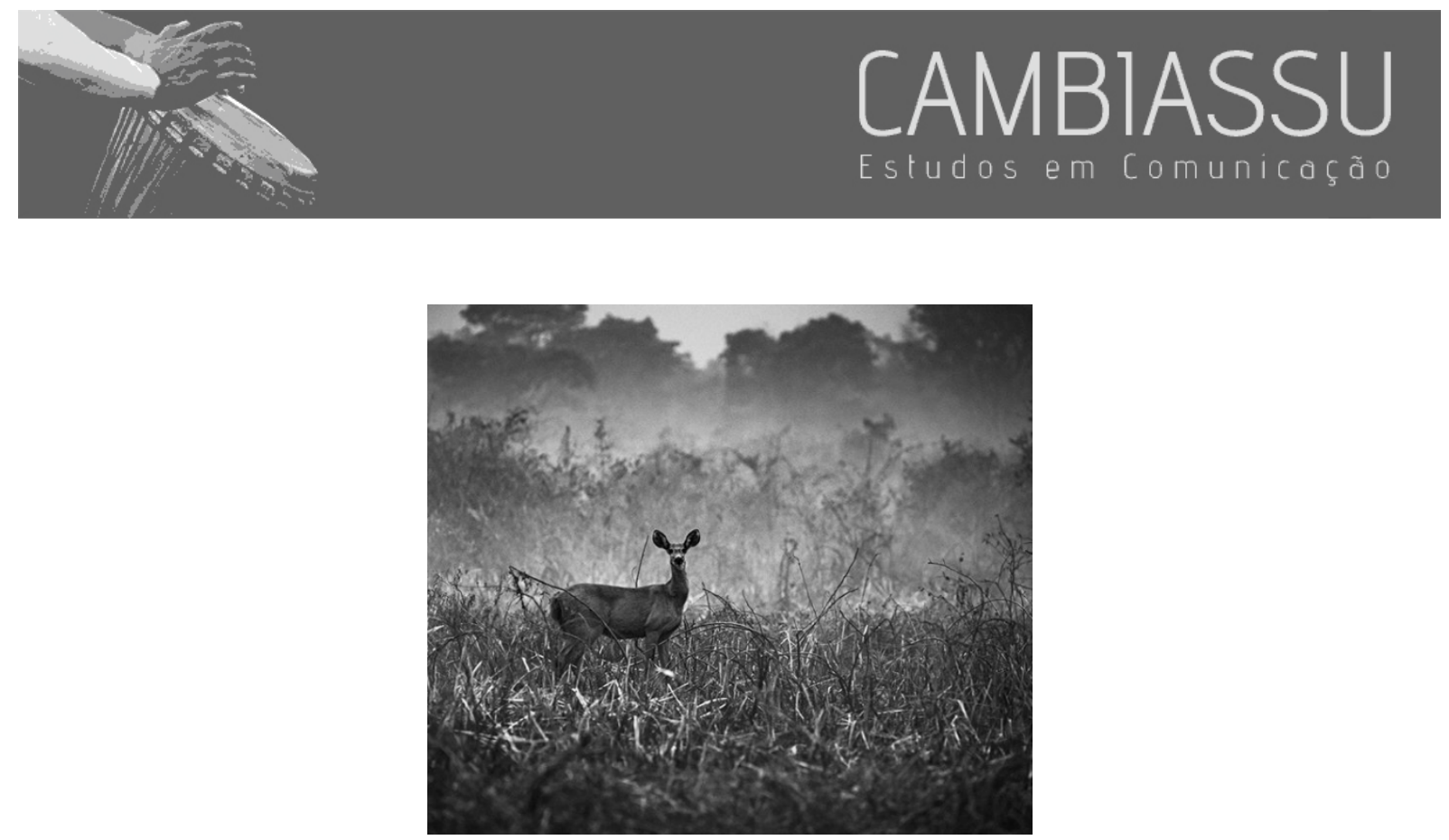

Fonte: ALCÂNTARA (2020, s/p).

Aqui notamos uma postura assustada empreendida pelo olhar animal em direção ao fotógrafo - e para nós também. A postura, questionadora e impositiva, como se nos direcionasse uma pergunta (“E agora?”), coloca em questão a (nossa) ação humana como responsável pelo mal que assola o ecossistema do Pantanal, de modo que ainda temos a audácia de registrar em fotografia a destruição que é de nossa responsabilidade. O inesperado olhar direto de uma das milhares de vítimas diretas desses incêndios nos causa desconforto, pois mesmo que a linguagem fotográfica não carregue o aspecto falado, não tenha a presença de uma voz concreta, ela traz as afetividades como materiais concretos o suficiente para comover angústias e inquietações. Além disso, há três camadas na imagem: no primeiro plano, o animal que nos olha; logo atrás, um nível de fumaça colocado de maneira nuançada; e, por último, o céu junto das árvores escuras. No convite que a fotografia nos faz para inserir, através da nossa imaginação, movimento e continuidade à cena, é possível nos perguntamos: é para lá, para o fundo, que o cervo, depois de olhar, vai fugir? Ele teria mais medo da presença humana em seu ambiente natural do que o próprio fogo? Não seria esse fogo destruidor menos assustador, pois a nossa presença parece ser a causa principal de tamanho medo?

Esse olhar animal presente na fotografia, junto à escolha de tons em preto e branco, são aspectos característicos do jornalismo ambiental, pois essa prática faz uso de um horizonte poético e de nuances artísticas para reforçar o sentido da copresença, da troca entre cervo e fotógrafo. Além 


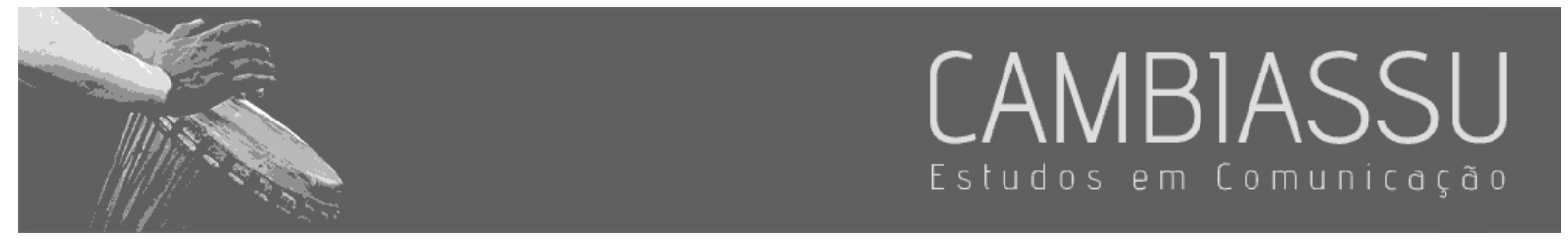

disso, ao se colocar numa posição de alguém que está sendo questionado profundamente, Alcântara dinamiza o ativismo ecológico que nos leva a perguntar sobre os traços e as consequências que estamos impondo ao meio ambiente. Possivelmente, pela capacidade de fazer figurar relações tão complexas em cenas tão singulares, essa ferramenta questionadora colocada em uso pela fotografia ambiental nos leve a considerar uma nova forma de relação com a natureza e, sobretudo, uma nova forma de relação com o conhecimento, pensando pluralmente ao invés de monoculturalmente.

Figura 4: Quase perco a anta atravessando a Transpantaneira tomada pela fumaça

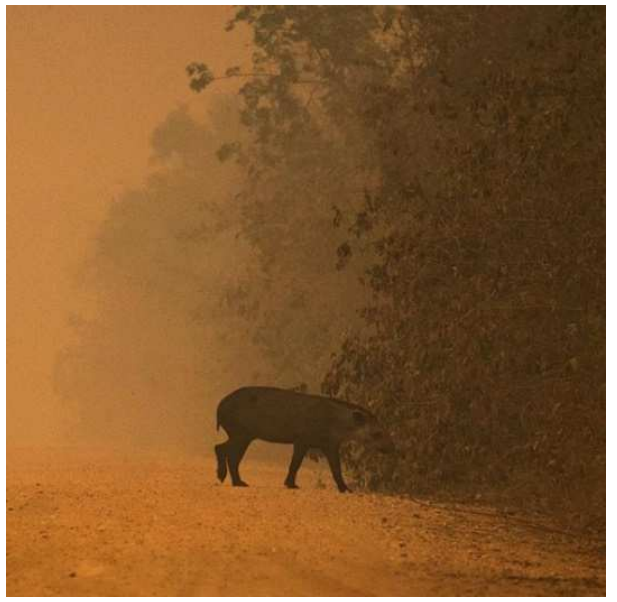

Fonte: ALCÂNTARA (2020, s/p).

A anta caminha desolada, sequer tem forças para lutar pela própria vida. A morte, aqui, foi aceita e digerida. O fim apaziguado. Entretanto, é como se o animal ganhasse uma posição secundária em termos de relevância fotográfica, mesmo que seja o centro de interesse de Alcântara. Aqui é o fogo o personagem principal, tomando conta de quase toda a composição, deixando o animal diminuto por efeito de comparação e criando um ambiente completamente tomado pela fumaça alaranjada. Nada se vê bem. Um caminho (a Transpantaneira) onde não parece haver início nem fim, sem perspectiva, sem futuro, desolador. É a névoa enfumaçada do incêndio o elemento que cria para nós a sensação angustiante e paralisante. Sentimos uma certa solidão pela postura e forma de aparição do animal, prostrado, sozinho em meio ao cenário, sem provavelmente reconhecer mais o seu habitat, sem sentir mais a legitimidade da sua própria presença ali. Os demais elementos, como a mata seca e o chão 


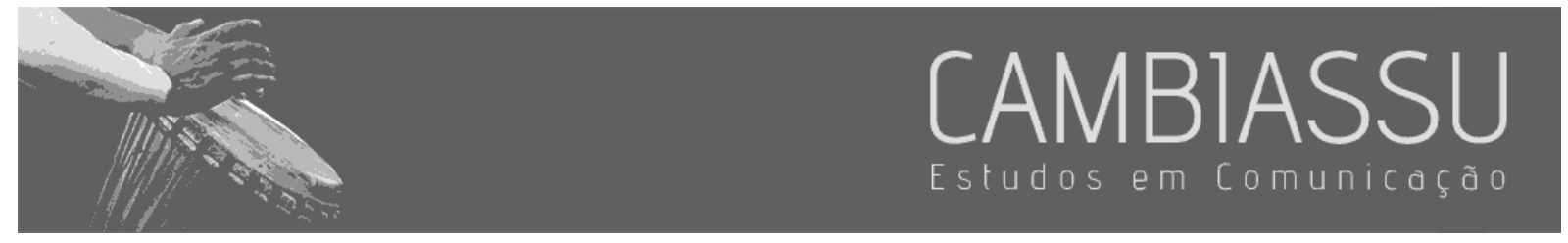

terroso, também nos indicam aspectos da morte iminente, pois cria um espaço no qual não é possível sequer respirar - a fumaça do fogo abraça os pulmões. "Quem eu sou?" "Para onde eu vou?" Por fazer com que um animal abandone a vontade de lutar pela própria vida, inferimos que uma dor profunda transformou a luta em uma aceitação da derrota. Nós estamos derrotados.

Acreditamos que essa é uma escolha sensível prevista no horizonte poético do fotógrafo, isto é, colocar em imagem uma cena de derrota, ao mesmo tempo em que, em seu trabalho, se mostra preocupado em retratar as belezas como mecanismos de motivação e esperança.

\section{Considerações finais}

Compreendemos, com a leitura simbólica das fotografias, que a poética da fotografia ambiental não fala sobre um elemento artístico somente belo, que retrata as belezas naturais brasileiras de maneira encantadora e atraente. A poética é também precisa no que se trata de trazer comoção, angústia e afeto. Se nos afastamos de uma questão moral, a qual ditaria o bom e o ruim do elemento poético, avançamos e entendemos que se trata de um acontecimento que precisa do nosso olhar afetivo. O que podemos entender como bom ou ruim é a queimada do Pantanal a partir das narrativas de imagens, mas, em contraponto, não podemos indicar elementos morais na poética da fotografia ambiental. Por isso, ela se torna uma prática com grande potencial transformador, pois nos é permitindo a entrega à imagem, sem conclusões prévias, que vemos o nosso ser inquietante palpitar e mudar o olhar para a natureza. Como propõe Unger (1991) sobre o (re)encantamento do humano, ele pode ser possível através da fotografia ambiental.

A cobertura ambiental, nas fotografias de Alcântara, acontece por meio de um contraste, de um fluxo entre duas abordagens específicas - o registro através de um horizonte poético apresentado nas imagens e a denúncia crítica que impõe força no seu trabalho. A iminência de algo está sempre presente: a morte que se aproxima de um animal no meio das cinzas (Figura 3), a queda que logo 


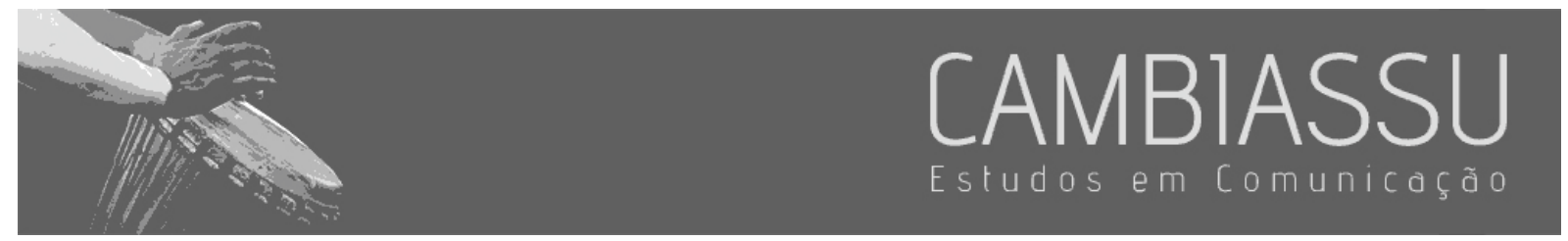

chegará ao macaco-prego que mergulha no ar (Figura 1) e o campo verde que será tomado pelo fogo destruidor a qualquer momento (Figura 2). As fotografias de Alcântara não narram apenas o presente, como seria esperado de um trabalho que traz características documentais e testemunhais, pois ele congela um olhar poético sobre o mundo que direciona a um possível acontecimento futuro e próximo - dito de outra forma, ele traz uma cobertura ambiental com uma abertura à imaginação que se propõe lutar contra o tempo que passa.

Considerando potências sociopolíticas do trabalho analisado, destacamos a possibilidade de transformação profunda imposta aos sujeitos que contatam as fotografias em questão. Isso porque, a partir das imagens, Alcântara nos indica os caminhos futuros pela iminência da morte e da queda, como descrito acima, ao mesmo tempo que nos puxa de volta ao presente. Em outras palavras, ele nos mostra as consequências tendo como ponto de partida as causas, de modo a criar um elo com as problemáticas atuais. É uma teia emaranhada de sentido que coloca em prática o jornalismo ambiental e o ativismo ecológico através do elemento visual da fotografia, dinamizando uma certa contextualização bastante ampla que diz respeito ao imaginário da cobertura pela via da fotografia ambiental. A imagem do fogo no Pantanal se encontra num limiar entre o aspecto metafórico e o aspecto literal, num limiar entre o contato com o simbólico que se apresenta no material fotográfico.

\section{Referências}

ALCÂNTARA, Araquém. A paisagem agora é essa. [s.I.], 8 de outubro de 2020. Instagram: araquemoficial. Disponível em: <https://www.instagram.com/p/CGGuxvllLSB/>. Acesso em: 29 set. 2020.

ALCÂNTARA, Araquém. Os macacos-prego fogem. [s.I.], 17 de setembro de 2020. Instagram: araquemoficial. Disponível em: < https://www.instagram.com/p/CFP0mkRpsPV/>. Acesso em: 29 set. 2020.

ALCÂNTARA, Araquém. Pegando fogo mesmo. [s.I.], 10 de outubro de 2020. Instagram: araquemoficial. Disponível em: < https://www.instagram.com/p/CGLXdF0leu5/>. Acesso em: 14 out. 2020.

ALCÂNTARA, Araquém. Quase perco a anta atravessando a Transpantaneira tomada pela fumaça. [s.I.], 25 de setembro de 2020. Instagram: araquemoficial. Disponível em: <https://www.instagram.com/p/CFICqnyl1Q8/>. Acesso em: 14 out. 2020.

BARROS, Ana Taís Martins Portanova. O que é o Sagrado no Instagram? Sacralização, dessacralização e ressacralização na cultura midiática. Revista Brasileira de Ciências da Comunicação, São Paulo, v. 42, n. 1, p. 131-151, 2019. 


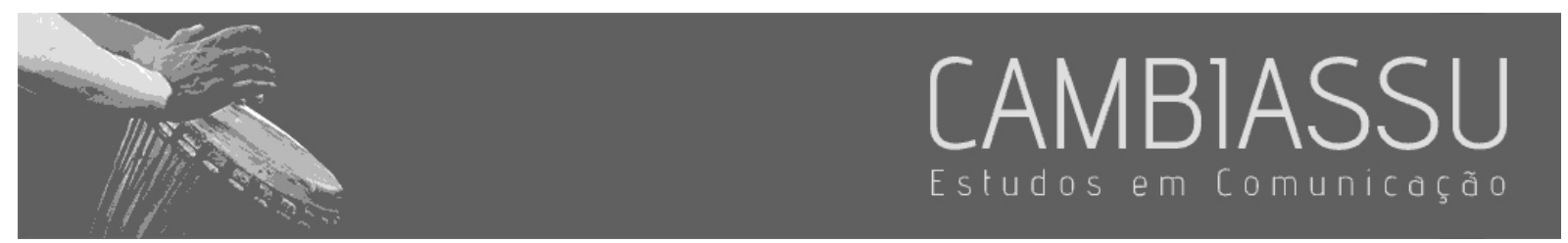

BELMONTE, Roberto. A construção do discurso da economia verde na revista Página 22. 2015. $180 \mathrm{f}$. Dissertação (Mestrado em Comunicação) - Programa de Pós-Graduação em Comunicação, Universidade Federal do Rio Grande do Sul, Porto Alegre, 2015.

DAMÁSIO, Kevin. Brasil já sente impactos das mudanças climáticas e situação pode se agravar. National Geographic, 13 fev. 2020. Disponível em: https://www.nationalgeographicbrasil.com/meioambiente/2020/02/brasil-ja-sente-impactos-das-mudancas-climaticas-e-situacao-pode-se-agravar. Acesso em: 12 out. 2020.

DE CARLI, Anelise Angeli. Entre o visível e o sentido: A comunicação como um pensamento por imagem. 2020. Tese (Doutorado) - Programa de Pós-Graduação em Comunicação, Universidade Federal do Rio Grande do Sul, Porto Alegre, 2020.

DURAND, Gilbert. A imaginação simbólica. Lisboa: Edições 70, 1995.

DURAND, Gilbert. As estruturas antropológicas do imaginário: introdução à arquetipologia geral. São Paulo: Martins Fontes, 1997.

FLUSSER, Vilém. Filosofia da caixa preta. São Paulo: Annablume, 2011.

GIRARDI, Ilza et al. Caminhos e descaminhos do jornalismo ambiental. Comunicação \& Sociedade, São Bernardo do Campo, v. 34, p. 132-152, 2012.

LACERDA, Rayane; DOMINGUEZ, Carlos André. Fotojornalismo ambiental: a sustentabilidade do olhar. In: ENCONTRO NACIONAL DE PESQUISADORES EM JORNALISMO AMBIENTAL, 4., 2019, Porto Alegre. Anais [...]. Porto Alegre: Grupo de Pesquisa em Jornalismo Ambiental, 2019.

LACERDA, Rayane; SANTOS, Francisco. O imaginário do olhar fotográfico ambiental. In: Pedagogia do Imaginário: Matrizes oníricas de uma Escola Viva, 1., 2019, Pelotas. Anais eletrônicos... Pelotas: Grupo de estudos e pesquisas sobre imaginário, educação e memória, 2019, p. 61-64.

LEITE, Carolline. Fotógrafo Araquém Alcântara registra fuga de animais e destruição das queimadas no Pantanal. Portal G1, São Paulo, 26 set. 2020. Disponível em:

<https://g1.globo.com/natureza/pantanal/noticia/2020/09/26/fotografo-araquem-alcantara-registra-fuga-deanimais-e-destruicao-das-queimadas-no-pantanal.ghtml>. Acesso em: 07 out. 2021.

LEMOS, Vinícius. As imagens de animais que lutam pela vida em meio a incêndios no Pantanal. BBC News Brasil, São Paulo, 21 set. 2020. Disponível em: <https://www.bbc.com/portuguese/brasil-58564851>. Acesso em: 07 out. 2021.

MARTINS, Ana Taís. Narrativas na Comunicação: a persistência mitogênica. Alceu - Revista de Comunicação, Cultura e Política, Rio de Janeiro, v. 20, n. 40, 2020.

RODRIGUES, Alex. PF e órgãos estaduais apuram causas de incêndios no Pantanal. Agência Brasil, Brasília, 18 set. 2020. Disponível em: <https://agenciabrasil.ebc.com.br/geral/noticia/2020-09/pf-e-orgaos-estaduaisapuram-causas-de-incendios-no-pantanal>. Acesso em: 07 out. 2021.

SHIVA, Vandana. Monoculturas da mente: perspectivas da biodiversidade e da biotecnologia. São Paulo: Gaia, 2003.

UNGER, Nancy Mangabeira. Crise ecológica: a deserção do espaço comum. Educação \& Realidade, Porto Alegre, v. 34, n. 3, 2009. Disponível em: <https://seer.ufrgs.br/educacaoerealidade/article/view/9542/0>. Acesso em: 12 out. 2020 .

UNGER, Nancy Mangabeira. O encantamento do humano: ecologia e espiritualidade. São Paulo: Edições Loyola, 1991. 